\title{
Correspondence
}

We welcome letters to the Editor concerning articles which have recently been published. Such letters will be subject to the usual stages of selection and editing; where appropriate the authors of the original article will be offered the opportunity to reply.

Letters should normally be under 300 words in length, double-spaced throughout, signed by all authors and fully referenced. The edited version will be returned for approval before publication.

\section{Transient osteoporosis of the hip}

Sir,

The article by Karagkevrekis and Ainscow ${ }^{1}$ in the January 1998 issue entitled 'Transient osteoporosis of the hip associated with osteogenesis imperfecta (OI)' described two patients with OI who developed migratory transient osteoporosis (MTO) associated with a stress fracture. They state that the condition is extremely rare in association with OI but we have listed 13 other cases in our review article. ${ }^{2}$ Sequential involvement in the same or other joints has been reported in $41 \%$ of cases of $\mathrm{TO}^{3}$, and MTO in OI was observed to occur in five out of 17 patients $(29 \%){ }^{2}$ Dual-energy X-ray absorptiometry (DEXA) may be helpful as well as MRI in estimating the degree of osteoporosis and may rule out an underlying disease. These investigations may be used to monitor the clinical course and to assess the effect of treatment. Although conservative management is usually successful, core decompression has been suggested to increase clinical improvement. ${ }^{4}$ Pathological fractures are rare and have been seen in only seven of over 500 reported cases of TO. Microfractures, seen on histological examination, may play a role in the early pathophysiology of patients with MTO and OI.

P. I. J. M. WUISMAN, MD, PhD

R. J. P. NOORDA, MD

University Hospital 'Vrije Universiteit'

Amsterdam, The Netherlands.

1. Karagkevrekis CB, Ainscow DAP. Transient osteoporosis of the hip associated with osteogenesis imperfecta. J Bone Joint Surg [Br] 1998; 80-B:54-5.

2. Noorda RJP, van der Aa JPW, Wuisman PIJM, et al. Transient osteoporosis and osteogenesis imperfecta: a case report. Clin Orthop 1997;337;249-55.

3. Lakhanpal S, Ginsburg WW, Luthra HS, Hunder GG. Transient regional osteoporosis: a study of 56 cases and review of the literature. Ann Intern Med 1987;106:444-50.

4. Hofmann S, Engel A, Neuhold A, et al. Bone-marrow oedema syndrome and transient osteoporosis of the hip: an MRI-controlled study of treatment by core decompression. J Bone Joint Surg $[\mathrm{Br}]$ 1993;75-B:210-6.

\section{Author's reply:}

Sir,

Thank you for the important points which you have raised about the association between osteogenesis imperfecta and transient

C(C1998 British Editorial Society of Bone and Joint Surgery

0301-620X/98/49118 $\$ 2.00$

J Bone Joint Surg [Br] 1998;80-B:743-7.

VOL. 80-B, No. 4, JULY 1998 osteoporosis of the hip. Unfortunately, your article in Clinical Orthopaedics and Related Research was published after submission of our paper. In the paper which suggested the use of core decompression for persistent symptoms in transient osteoporosis, none of the patients had OI. This invasive procedure could potentially cause pathological fractures in patients with OI.

\section{B. KARAGKEVREKIS, FRCS}

Alexandra Hospital

Redditch, UK.

1. Hofmann S, Engel A, Neuhold A, et al. Bone-marrow oedema syndrome and transient osteoporosis of the hip: an MRI-controlled study of treatment by core depression. J Bone Joint Surg [Br] 1993; 75-B:210-6.

\section{Chondrocyte transplantation using a collagen bilayer matrix for cartilage repair}

Sir,

I read with interest the paper by Frenkel et al $^{1}$ in the September 1997 issue entitled 'Chondrocyte transplantation using a collagen bilayer matrix for cartilage repair'. What was the age of the New Zealand White rabbits used as donors for the cartilage cultures and from what site was the specimen obtained?

The authors state that "Transplantation of osteochondral grafts, periosteum and cultured chondrocytes... have not produced long-lasting hyaline cartilage." Peterson, Minas and Borgstoen, ${ }^{2}$ however, have obtained biopsies containing hyaline cartilage more than five years after implantation of cultured chondrocytes, and osteochondral autografting has also been shown to have hyaline cartilage on biopsy several years after implantation.

S. I. SILAS, MD

New Smyrna Beach

Florida, USA.

1. Frenkel SR, Toolan B, Menche D, Pitman MI, Pachence JM. Chondrocyte transplantation using a collagen bilayer matrix for cartilage repair. J Bone Joint Surg [Br] 1997;79-B:831-6.

2. Peterson L, Minas T, Borgstoen S. Review of the clinical experience with autologous chondrocyte implantation for the treatment of articular defects of the knee. AAOS Annual Meeting, San Francisco, February 1997.

3. Stone K. Articular cartilage autografting. 22nd Annual Meeting of AOSSM, Orlando, June 1977.

\section{Author's reply:}

Sir,

I thank Dr Silas for his comments. The age of the rabbits was nine months. Allograft chondrocytes were implanted; they were not taken from any one site but were harvested from the distal femur, the tibial plateau, and the scapula of several donors and then pooled.

Dr Silas states that at the AAOS Annual Meeting in 1997, Peterson et al demonstrated hyaline cartilage in biopsies taken more than five years after the transplantation of chondrocytes but I was not aware of that presentation. Their published human data ${ }^{1}$ included a single photomicrograph from a biopsy after 36 months 
which indeed shows a small area of hyaline-appearing cartilage. Dr Silas also refers to Stone's work with osteochondral transplantation. $^{2}$ In a more recent presentation, Stone reported a technique using morsellised osteochondral autograft packed into an articular cartilage bed which had been prepared by microfracture. ${ }^{3}$ In biopsies of 16 patients with a follow-up of more than one year, seven showed repair of hyaline cartilage, seven mixed hyaline and fibrocartilage, and two predominantly fibrocartilage. Pain relief was reported by the patients to be excellent. While research strives to develop improved methods for regeneration of durable hyaline cartilage, the cited techniques are certainly contributing to the clinical improvement of the patients as illustrated in a recent paper by Brittberg et al. ${ }^{4}$ The goal is to relieve pain and restore function until permanent restoration of defective articular surfaces can be achieved.

\section{S. FRENKEL, PhD}

Hospital for Joint Diseases

New York, USA.

1. Brittberg M, Lindahl A, Nilsson A, et al. Treatment of deep cartilage defects in the knee with autologous chondrocyte transplantation. $N$ Engl J Med 1994;331:890-5.

2. Stone K. Articular cartilage autografting. 22nd Annual Meeting of AOSSM, Orlando, June 1977

3. Stone KR, Walgenbach AW. Surgical technique and initial results for articular cartilage transplantation to traumatic and arthritic defects in the knee joint. Trans Orthop Res Soc 1998;23:150

4. Brittberg M, Lindahl A, Nilsson A, et al. Autologous cartilage cell transplantation: the goal is pain relief and restored joint function. Nord Med 1995;110:330-4.

\section{Planovalgus and cavovarus deformity of the hind foot}

Sir,

We read with interest the 'Topic for Debate' in the November 1997 issue entitled 'Planovalgus and cavovarus deformity of the hind foot'.

Professor Klaue argued for a new understanding and functional approach to managing complex deformities of the hind foot. We have concerns that his explanation of the anatomical deformities present in club foot is at variance with established understanding. His Figure 1a purports to show deformities in a club foot which suggest that the neck and head of the talus are angulated laterally and that the navicular subluxates medially on the head of the talus. Our own anatomical studies ${ }^{2}$ support the work of other investigators who have shown that the typical deformity is of medial angulation of the neck and head of the talus ${ }^{3-7}$ (Fig. 1). It is agreed that the talar neck may be short and that this reflects in part the finding that the talus as a whole is smaller than normal. We have concerns that further medialisation of the talar head and neck would tend to subluxate the anterior and medial facets at the talocalcaneal joint leading to further incongruity and preventing subtalar movement.

We believe that osteotomy of the talar neck may impede the blood supply of the talus. It would certainly be wise to see an established series published before recommending it only on an anecdotal basis.

C. B. HOWARD, FRCS

S. PORAT, MD, MCh Orth

Hadassah University Hospital

Jerusalem, Israel.

M. K. D. BENSON, FRCS

Nuffield Orthopaedic Centre

Oxford, UK.

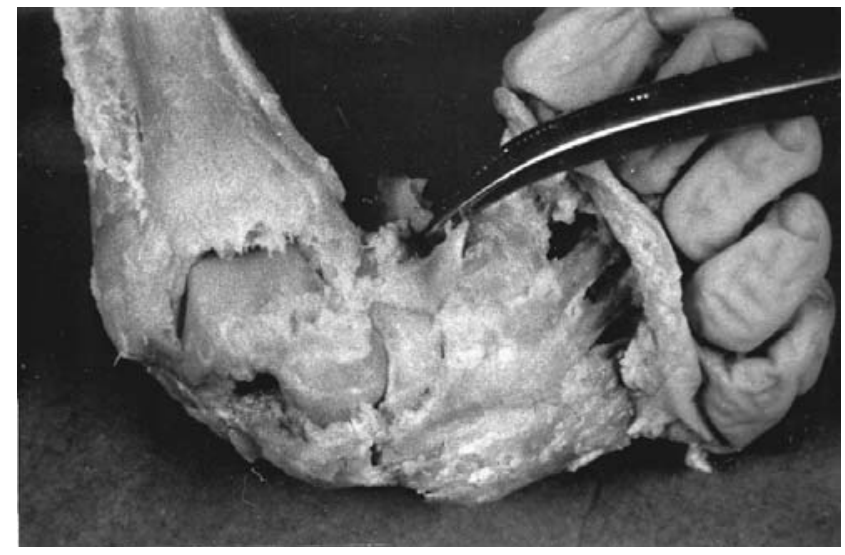

Fig. 1

The medially deviated neck and head of the talus in a dissected specimen of neonatal club foot.

1. Klaue K. Planovalgus and cavovarus deformity of the hind foot. J Bone Joint Surg [Br] 1997;79-B:892-5.

2. Howard CB, Benson MKD. Clubfoot: its pathological anatomy. J Pediatr Orthop 1993;13:654-9.

3. Adams W. Clubfoot: its causes, pathology and treatment. 2nd edition. London: JA Churchill, 1873.

4. Hjelmstedt B, Sahlstedt B. Talar deformity in congenital clubfeet: an anatomical and functional study with special reference to the ankle joint mobility. Acta Orthop Scand 1974;45:628-40.

5. Irani RN, Sherman MS. The pathological anatomy of clubfoot. J Bone Joint Surg [Am] 1963;45-A:45-52.

6. Settle GW. The anatomy of congenital talipes equinovarus: sixteen dissected specimens. J Bone Joint Surg [Am] 1963;45-A:1341-54.

7. Waisbrod H. Congenital clubfoot: an anatomical study. J Bone Joint Surg [Br] 1973;55-B:796-801.

\section{Author's reply:}

Sir,

I thank Messrs Howard and Benson and Dr Porat for their interest in my work which contrasts with their study in children.

I would like to comment on the subluxation of the 'coxa pedis' in which the head of the talus subluxates laterally out of the navicular cup due to the pull of extrinsic musculature. I refer to the work of Epeldegui and Delgado.

Howard and Benson discuss the optimal articular reorientation possible in the early months and years of life, which is without doubt the best treatment. I have discussed the residual deformity in the mature and adult foot, in which such reorientation of the articular surfaces is not possible. The typical deformity is a medial angulation of the head of the talus which corresponds to an adaptation of a false position of the navicular in relation to the head of the talus. The concerns about the subluxation of the anterior and medial facets at the talocalcaneal joint have been addressed by proposing the kind of correction which I have advocated. It may be compared with the hip when the subluxing femoral head in a shallow acetabulum may be shifted down to a more physiological centre of rotation through a varus osteotomy of the proximal femur.

Vascularity of the posterior part of the talus is not affected because the main blood supply is below the medial malleolus. The talar head is not usually affected with regard to blood supply in cases of trauma. 
I agree that it would be wise to study an established series before recommending such procedures on a wide scale. We now have six years of experience and have not had any problems related to the vascularity of the talus.

K. KLAUE, MD

ATOS Klinik

Heidelberg, Germany.

1. Epeldegui T, Delgado E. Acetabulum pedis. Part I: Talocalcaneonavicular joint socket in normal foot. $J$ Pediatr Orthop $B$ 1995;4:1-10.

2. Epeldegui T, Delgado E. Acetabulum pedis. Part II. Talocalcaneonavicular joint socket in clubfoot. J Pediatr Orthop B 1995;4:11-6.

\section{Severe osteolysis after third-body wear due to hydroxyapatite particles from acetabular cup coating}

\section{Sir}

I read with interest the report by Morscher et al in the March 1998 issue concerning osteolysis associated with HA-coated polyethylene acetabular components. ${ }^{1}$ They used energy-dispersive X-ray spectroscopy to identify particles of calcium phosphate on the articular aspect of worn polyethylene cups, and attribute osteolysis to third-body abrasive wear from HA debris.

Third-body debris is an important concern in total hip arthroplasty, but the reported observations should be interpreted with caution for several reasons. First, the methods used do not confirm that the hydroxyapatite granules are derived from the implant. Energy-dispersive X-ray (EDX) spectroscopy shows calcium and phosphate, but additional analytical techniques, such as infrared spectroscopy are required to distinguish exogenous HA from bone and from artifactual precipitation of calcium phosphates from joint fluid or other solutions. The carbon and oxygen identified on the implant could represent polyethylene, but could also be derived from other sources. Secondly, no control cups were included in the study. This is important because previous authors have used EDX to demonstrate calcium phosphate particles adherent to acetabular polyethylene in the absence of HAcoated implants. ${ }^{2}$ Thirdly, no control femoral heads were included. We have previously reported scratched heads associated with failed HA-coated total joint prostheses, but these heads had fewer and more shallow scratches than those from porous or cemented implants matched by duration in vivo. ${ }^{3}$ Finally, no clinical controls are described in this study. Osteolysis is a well-recognised complication of hip arthroplasty, especially with $32 \mathrm{~mm}$ femoral heads. The authors express concern about osteolysis developing nine to 15 years after arthroplasty in ten of 460 cases with HAcoated implants, but give no information about the incidence of osteolysis associated with similar implants without HA coatings. Indeed, with a revision rate for osteolysis of $2.2 \%$ at nine to 15 years, this implant may have a lower incidence of osteolysis than many other designs. Without adequate controls it is inappropriate to claim that osteolysis is "due to HA particles".

In spite of the above considerations, it is possible that the debris described by Morscher et al represents HA. This would not be surprising given the design of the implants which they studied. In part due to the large mismatch in modulus of elasticity between HA coatings and polyethylene, the layers of HA granules heatpressed into the PE cups in their study are much more likely to delaminate than thin, plasma-sprayed HA coatings on appropriately textured metal substrates. Consequently, the conclusions of their study should be restricted to 'all-polyethylene' acetabular components with thick coatings of heat-pressed HA granules, not metal implants with thin, plasma-sprayed HA coatings. Although the contribution of HA debris to osteolysis in the reported cases is vague at best, I agree in principle that manufacturers should strive for a high bond strength and appropriate match in modulus between substrate and any potentially abrasive surface treatment.

T. W. BAUER, MD, PhD

The Cleveland Clinic Foundation

Cleveland

Ohio, USA

1. Morscher EW, Hefti A, Aebi U. Severe osteolysis after third-body wear due to hydroxyapatite particles from acetabular cup coating. J Bone Joint Surg [Br] 1998;80-B:267-72.

2. Bloebaum BD, Beeks D, Door LD, et al. Complications with hydroxyapatite particulate separation in total hip arthroplasty. Clin Orthop 1994;298:19-26.

3. Bauer TW, Taylor SK, Jiang M, Medendorp SV. An indirect comparison of third-body wear in retrieved hydroxyapatite-coated, porous, and cemented components. Clin Orthop 1994;298:11-8.

\section{Authors' reply:}

Sir,

We appreciate your comments regarding our interpretation of the SEM data included in our recent publication. As you acknowledge, the 'granules' depicted by SEM on the inner surface of HAcoated cups which have been removed clearly represent HA-containing deposits as indicated by the $\mathrm{Ca}$ and $\mathrm{P}$ peaks in the corresponding EDX spectra. You raise the possibility that these do not arise from the acetabular HA cup coating after third-body wear but are calcium phosphate particles adherent to acetabular polyethylene in the absence of HA-coated implants. Based on an unpublished SEM investigation which we performed some years ago for Protek AG comparing new with removed uncoated polyethylene cups, this is clearly not so. First, the scratch/wear and deposit patterns on the inner surface of the cups never showed the type of adherent granule seen in the present study (see Figs 4a and 4b). Secondly, while we did show small $\mathrm{Ca}$ and $\mathrm{P}$ peaks in the corresponding EDX spectra, these were at least $\times 10$ smaller than those in the present study. We are confident therefore that what we have imaged by SEM and evaluated by EDX are HA particles directly related to the coating of the acetabular cup.

In the same investigation we noted that the abundant randomly orientated deep scratches found in two cases were not present in any significant numbers when compared with similar SEM images recorded from femoral heads from patients with uncoated acetabular polyethylene cups. While these deep scratches may have been caused by HA particles, the fine scratches, since they are also produced in the absence of HA coatings, are due to a different cause.

\section{E. W. MORSCHER, MD}

University of Basel

Basel, Switzerland.

U. AEBI, PhD

A. HEFTI

M E Müller Institute

Basel, Switzerland.

Sir,

I read with interest the article in the March 1998 issue by Morscher et al entitled 'Severe osteolysis after third-body wear due to hydroxyapatite particles from acetabular cup coating'.

Between 1977 and 1979 Professor J-F Osborn worked in Basel with Professor Spiessl and was aware that Professor Morscher was experimenting with this form of attachment of hydroxyapatite 
ceramic granules to polyethylene. It was well known that the method used, namely hot-isostatic pressing, did not succeed.

Now, years later, the author has published the predicted failures as a deficiency of hydroxyapatite ceramic rather than as an inappropriate method of application.

This is a wrong and unfair conclusion.

\section{R. FURLONG, FRCS}

Wimpole Street

London W1M 7AB, UK.

1. Morscher EW, Hefti A, Aebi U. Severe osteolysis after third-body wear due to hydroxyapatite particles from acetabular cup coating. J Bone Joint Surg [Br] 1998;80-B:267-72.

\section{Author's reply:}

Sir,

I thank Mr Furlong for his comment.

The point of our study was to find the cause of the severe osteolysis observed in hydroxyapatite (HA)-coated acetabular cups and not to criticise or evaluate the HA coating from the manufacturing point of view. The introduction of $\mathrm{HA}$ as a coating for RM-HDPE cups in 1982 was an advance from the cementless cups used until then and they worked very well at that time. It took ten years before excessive third-body wear and osteolysis due to HA particles caused symptoms in a limited number of cases! My concerns about the disintegration of HA from the cup surface and migration of the particles into the joint space were theoretical and hypothetical, but they were reason enough for me to abandon the use of HA coating after a few years.

There is no doubt about the improvements in the quality of the HA coating in the last 15 years, but the basic principles of the disintegration of HA have also remained the same. Furthermore, disintegration has been observed and described in 'modern' HA coatings. This is still considered by many as 'unusual' without any clinical consequences.

The only good test of theory is practice. In our article we were able to demonstrate that HA coating can cause severe osteolysis in the long term. Is it therefore unfair to recommend that follow-up of implants with HA coating be continued?

\section{E. W. MORSCHER, MD}

University of Basel

Basel, Switzerland.

\section{Fixation of fractures of the clavicle with Kirschner wires}

\section{Sir}

We were very concerned by the article by Ngarmukos, Parkpian and Patradul ${ }^{1}$ in the January 1998 issue which recommends fixation of clavicular fractures by Kirschner wires. It may be that certain techniques of wire fixation about the shoulder are safer than others but the potential dangers, owing to wire migration, are well known. Knowledge of a single example, such as that in which a wire migrated from a sternoclavicular joint to the bottom of the pericardial sac within nine weeks in a 14 -year-old boy, ${ }^{2}$ should be enough to discourage most from this practice.

We consider that any surgeon contemplating using wires about the shoulder must be aware of the dangers and be meticulous in their postoperative management to minimise the risks. These are clearly set out by Lyons and Rockwood. ${ }^{3}$

The use of wires for dislocation or fracture fixation about the shoulder should be strongly discouraged and we are concerned that an article such as that published will have the opposite effect.
J. A. HOPKINSON-WOOLLEY, MSc, FRCS

C. R. CONSTANT, LLM, MCh, FRCS

Addenbrooke's Hospital

Cambridge, UK.

1. Ngarmukos C, Parkpian V, Patradul A. Fixation of fractures of the midshaft of the clavicle with Kirschner wires. J Bone Joint Surg [Br] 1998;80-B:106-8.

2. Fowler AW. Letter to Editor. Injury 1981;13:261-2.

3. Lyons FA, Rockwood CA Jr. Migration of pins used in operations on the shoulder. J Bone Joint Surg [Am] 1990;72-A:1262-7.

\section{Author's reply:}

Sir,

We are well aware of the potential dangers of the fixation by Kirschner $(\mathrm{K})$ wires around the shoulder not only from the literature but from our own experience. This stimulated us to devise the technique described before the advent of the reconstruction plate which may be bent to conform to the shape of the clavicle. Our experience with previous plates was of failure because of loosening, nonunion and the unsightly scar. Only a few screws could be fixed in each fragment and we have had to use our technique to overcome this. We have compared reconstruction plates with $\mathrm{K}$ wires in only a few selected patients because of the expense. So far there has been no loosening or nonunion but the plate had to be bent and twisted to conform to the shape of the clavicle. All plates had to be removed after union under general anaesthesia because the screw heads were prominent and the patients could not put a sling or backpack around their shoulders.

I believe that the technique which we describe has advantages particularly in the management of nonunion and in our country where cost has to be considered. As an experienced surgeon I realise that no matter how good the techniques or how perfect the surgery there will be some complications. I believe that K-wire fixation around the shoulder outweighs its disadvantages but patients should be told about its potential complications.

C. NGARMUKOS, MD

Chulalongkorn University

Bangkok, Thailand.

\section{Long-term results of late non-operative reduction of developmental dysplasia of the hip}

Sir,

In their article in the January 1998 issue entitled 'Long-term results of late non-operative reduction of developmental dysplasia of the hip' Kerry and Simonds stated that non-operative reduction had a very low rate of complication in late-presenting cases. ${ }^{1}$ The need for further treatment in $39 \%$ of their cases does not support this. Excellent results after secondary acetabular or proximal femoral procedures should not disguise the failure of primary procedures. The cost of their technique seems to be high because of a longer period of traction and a higher rate of secondary operations. We believe that assessment of the radiological results by the Severin classification system is debatable since it has low levels of intra- and interobserver reliability. ${ }^{2}$

The authors describe seven hips which were diagnosed between the ages of 19 and 36 months. We realise the difficulty in achieving satisfactory results without performing bony procedures in children over the age of 18 months $^{3}$, but would like to know how many of these hips required operation.

We have been performing a new technique in patients younger than 18 months since 1993. Through a medial approach we divide 
the adductor and iliopsoas tendons and confirm the concentric reduction by arthrography. We have observed medial pooling of the dye or a narrow safe zone in a few cases and have found that excision of ligamentum teres is the solution. Our encouraging results with this technique led us to abandon non-operative reduction of developmental dysplasia. We believe that arthrography is the most reliable method for confirmation of intraoperative reduction in patients younger than 18 months and suggest that failure to undertake this may have caused some hips with imperfect reduction to be missed in the series described.

H. ÖMEROĞLU, MD

A. BIÇIMOĞLU, MD

Ankara Numune Training and Research Hospital

Ankara, Turkey.

Y. TÜMER, MD

Ankara Güven Hospital

Ankara, Turkey.

1. Kerry RM, Simonds GW. Long-term results of late non-operative reduction of developmental dysplasia of the hip. J Bone Joint Surg [Br] 1998;80-B:78-82.

2. Ward TW, Vogt M, Grudziak JS, et al. Severin classification system for evaluation of the results of operative treatment of congenital dislocation of the hip: a study of intraobserver and interobserver reliability. J Bone Joint Surg [Am] 1997;79-A:656-63.

3. Ömeroğlu H, Tabak AY, Biçimoğlu A. (Correspondence.) Ludloff's medial approach for open reduction of congenital dislocation of the hip. J Bone Joint Surg [Br] 1997;79-B:875.

\section{Author's reply:}

Sir,

I thank Professor Tümer for his interest in our paper and for drawing attention to his as yet unpublished series of developmental dysplasia (DDH) treated by open reduction through a medial approach. I note also his paper on the Severin classification. I became aware of this only as our paper was in the process of publication. All classifications have their weak points but are used until clearly superseded.

Our aim was simply to point out that, since traction has largely been abandoned and early operative reduction is the norm in late presentation of DDH, traction followed by simple manipulative reduction of the hip gives excellent results and, as we have shown in a relatively small series, complete absence of avascular necrosis of the femoral head. I believe that all of our primary reductions were concentric and over $60 \%$ required no further treatment. I fully accept that a significant proportion required operation but in none of these was opening the capsule of the hip or interference with it necessary.

As regards the hips diagnosed after 18 months, these have not generally had a higher rate of late operative intervention, although case 4 described in our paper, which presented at 37 months, is not one of our better results. I think that this reflects the difficulty of treatment of very late presentation rather than the technique used. Most surgeons seem to agree that presentation after the age of two years reduces the likelihood of a good result.

It will be interesting to see the results of Professor Tümer's series in due course, particularly as regards avascular necrosis, but it is very early to assess this particular method of treatment. Our series has a mean follow-up of 11 years.

I have never felt arthrography to be necessary, or indeed to be entirely without risk, in infants and did not use this before traction or before manipulative reduction although we have done so before surgery. None of these cases showed imperfect reduction. The advent of CT and other methods of scanning has now radically changed the situation since our series began.
I do note that Professor Tümer finds the ligamentum teres to be an obstructing factor. I have long thought the role of the limbus to be overstated and did not have to open the capsule to excise the ligamentum teres in the hips in our series.

G. W. SIMONDS, MCh Orth, FRCS

Doncaster Royal Infirmary

Doncaster, UK.

\section{Synthetic porous ceramic compared with autograft in scoliosis surgery}

Sir,

I read with interest the recent paper in the January 1998 issue entitled 'Synthetic porous ceramic compared with autograft in scoliosis surgery' by Ransford et al. ${ }^{1}$ They propose the use of a synthetic porous ceramic (Triosite) as a substitute for bone graft in posterior spinal fusion for idiopathic scoliosis. In the group treated with synthetic ceramic they also used local bone graft. The average amount of synthetic ceramic used was 17 blocks of $1 \mathrm{~cm}$ and 16 blocks of $2 \mathrm{~cm}$ which I have calculated would be a total volume of $12.5 \mathrm{~cm}^{3}$. The volume of local bone graft used was $36 \mathrm{~cm}^{3}$, so that the porous ceramic is just $25 \%$ of the total volume of the implanted osteoconductive material.

From the data, it cannot be concluded that this material is a substitute for bone graft. It can be considered as a complementary osteoconductive material that helps to reduce the amount of autologous bone needed. Although Triosite may be a help, it should not be called a substitute, a term that is misleading.

C. B. MOLANO, MD

University of Iowa Hospital and Clinics

Iowa City, USA.

1. Ransford AO, Morley T, Edgar MA, et al. Synthetic porous ceramic compared with autograft in scoliosis surgery: a prospective, randomised study of 341 patients. J Bone Joint Surg [Br] 1998;80-B:13-8.

\section{Author's reply:}

Sir,

There is no contradiction between Dr Bernardino's letter and our paper.

When undertaking posterior spinal fusion in scoliosis surgery a variable amount of autologous bone graft is obtained from laminar decortication, excision of facet joints and trimming of spinous processes. There is absolutely no point in discarding this. The question to be answered is whether supplementary additional bone graft should be taken from the iliac crest. Our findings show that there was no difference if the supplemental additional bone was autologous iliac-crest graft or artificial bone (in this case Triosite).

We did not address the question as to whether supplemental bone graft was necessary. The large blocks of Triosite used were so slow to incorporate that the answer is probably in the negative!

A further trial using small Triosite granules is required. Any Triosite must be buried beneath autograft. If it is not, it becomes engulfed by fibrous tissue and does not convert to bone.

We are at present carrying out a detailed histological review of biopsy specimens of the fusion mass from eight of the patients who had Triosite.

\section{A. O. RANSFORD, FRCS}

Royal National Orthopaedic Hospital

Stanmore, UK. 